association of $\mathrm{CHF}$ with greater severity [Katz severity index: median (IQR): $4(3-5)$ vs. $2(1-3)$ ], damage [mSDI: $3(2-4)$ vs $0(0-1)$ ], comorbidity [modified Charlson- excluding CV items: 4 (3-6) vs $1(1-3)]$ and both CV $(37.5 \%$ vs $6.7 \%$ ) and overall mortality ( $43.2 \%$ vs $4.7 \%$ ) ( $p<0.0001$ for all comparisons). Also, CHF patients were more refractory to SLE treatments $(33.3 \%$ vs $24 \%$, $\mathrm{p}=0.0377$ ) and were more frequently hospitalised due SLE [median $3(1-5)$ vs $1(0-2), p<0.0001]$. The results of the multivariable model are depicted in table 1.

Table 1. Congestive heart failure associated factors (multivariable analysis)

\begin{tabular}{lccc}
\hline & Odds Ratio & $95 \%$ Cl & P-value \\
\hline Sex (female) & 0.46 & $0.25-0.88$ & 0.0147 \\
Ischaemic cardiopathy & 7.96 & $4.01-15.48$ & $<0.0001$ \\
Cardiac arrhythmia & 7.38 & $4.00-13.42$ & $<0.0001$ \\
Pulmonary hypertension & 3.71 & $1.84-7.25$ & 0.0002 \\
Cardiac valvulopathy & 6.33 & $3.41-11.62$ & $<0.0001$ \\
Hospitalization (due to SLE) & 3.74 & $1.81-8.65$ & 0.0008 \\
Calcium or vitamin D & 5.29 & $2.07-16.86$ & 0.0015 \\
Antimalarials & 0.28 & $0.17-0.45$ & $<0.0001$ \\
mSDI * & 1.29 & $1.16-1.44$ & $<0.0001$ \\
\hline
\end{tabular}

${ }^{*} \mathrm{mSDI}=$ modified SLICC/ACR damage index (without cardiovascular items)

Conclusion: - $\mathrm{CHF}$ is a rather late complication of SLE.

- Patients with SLE and CHF have more severe SLE, with greater refractoriness to SLE treatments and higher overall mortality.

- Treatment with antimalarials, as routinely used in SLE patients, is not only safe to heart, but even appears to have a cardioprotective effect.

REFERENCES

[1] Rúa-Figueroa I, López-Longo FJ, Calvo-Alén J, et al. National registry of patients with systemic lupus erythematosus of the Spanish Society of Rheumatology: objectives and methodology. Reumatol Clin. 2014;10(1): 17-24.

Acknowledgements: Research Unit of Spanish Society of Rheumatology Disclosure of Interests: None declared

DOI: 10.1136/annrheumdis-2021-eular.1208

\section{POS0722 NEPHRITIS INCORPORATING BANFF CRITERIA EMPHASIZES THE IMPORTANCE OF TUBULOINTERSTITIAL CHANGES FOR CREATININE AND PROTEINURIA AT 12 MONTHS AFTER RENAL BIOPSY}

M. Plüß ${ }^{1}$, S. Hakroush ${ }^{2}$, N. Niebusch ${ }^{1}$, B. Tampe ${ }^{1}$, P. Korsten ${ }^{1}$.

${ }^{1}$ Universitätsmedizin Göttingen, Department of Nephrology and Rheumatology, Göttingen, Germany; ${ }^{2}$ Universitätsmedizin Göttingen, Institute of Pathology, Göttingen, Germany

Background: Lupus nephritis (LN) occurs in about $30-60 \%$ of patients with systemic lupus erythematosus (SLE). $L N$ is associated with increased mortality. Currently, the diagnosis relies on histopathologic characteristics according to the ISN/RPS classification (1). This classification relies heavily on glomerular changes and may not accurately reflect all changes occurring in LN. For the description of transplanted kidney, the BANFF classification has been established which, in addition to glomerular changes, also incorporates tubular pathologies (2).

Objectives: With the present study, we aim to describe histopathologic changes according to the BANFF classification in a single-center cohort of LN patients. Methods: We retrospectively recorded epidemiological, clinical and laboratory data of 58 patients with LN over a ten-year period. Histopathologic diagnoses according to ISN/RPS classification or the former WHO classification were also documented. We then re-analyzed representative kidney samples according to the BANFF classification and performed Spearman rank correlation for BANFF findings and creatinine at biopsy and 12 months as well as proteinuria at biopsy and at 12 months.

Results: We analyzed 58 patients with LN. 9 were male, 49 were female. Median age was 38 (15-78) years. According to ISN/RPS, 3 had class I LN, 6 had class II, 14 had class III, 16 had class IV, 6 had class V, and 0 had class VI. Median eGFR at biopsy was $60 \mathrm{ml} / \mathrm{min} / 1.73 \mathrm{~m} 2$ (13-137). According to the BANFF classification, tubulointerstitial inflammation (ti) was associated with creatinine at 12 months. Proteinuria at 12 months was associated with interstitial fibrosis (ci) (Figure 1).
A

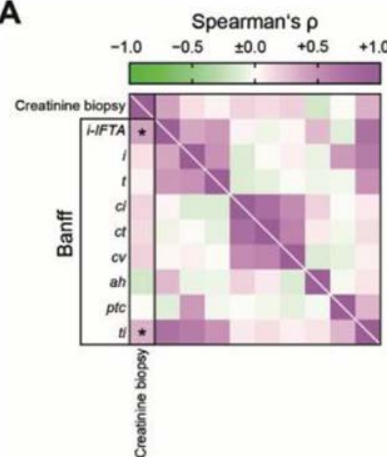

B
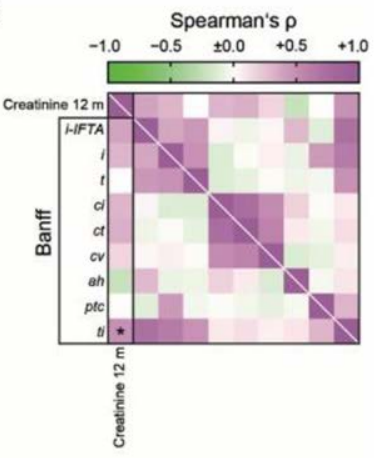

C

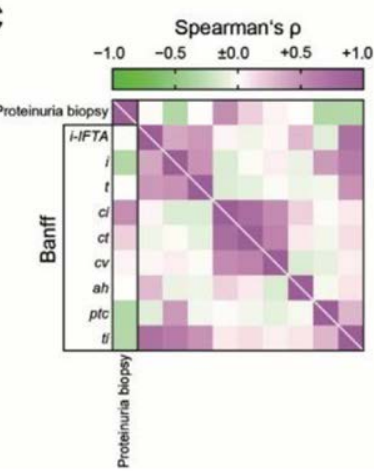

D

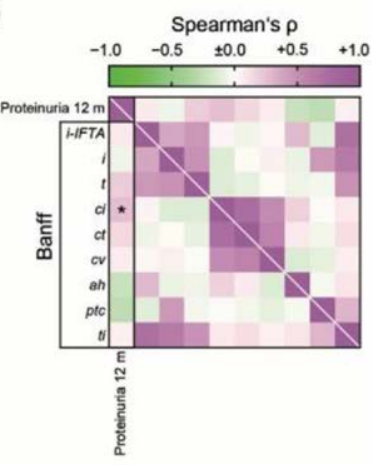

Conclusion: In LN, the current ISN/RPS classification puts emphasis on glomerular changes. Nevertheless, for the long-term outcome, tubulointerstitial changes (tubulointerstitial inflammation and interstitial fibrosis) may at least be as important as glomerular changes. These findings have to be corroborated in larger cohorts with prespecified renal endpoints.

\section{REFERENCES:}

[1] Weening et al. The classification of glomerulonephritis in systemic lupus erythematosus revisited. JASN 2004

[2] Jeong HY. Diagnosis of renal transplant rejection: Banff classification and beyond. Kidney Res Clin Pract 2020.

Disclosure of Interests: Marlene Plüß: None declared, Samy Hakroush: None declared, Noah Niebusch: None declared, Björn Tampe: None declared, PETER KORSTEN Speakers bureau: Abbvie, Pfizer, Chugai, Sanofi, Boehringer-Ingelheim, GSK, Novartis, Consultant of: Abbvie, Pfizer, Chugai, Sanofi, Boehringer-Ingelheim, GSK, Novartis, Lilly, Gilead, Grant/research support from: GSK DOI: 10.1136/annrheumdis-2021-eular.1213

\section{POS0723 HERPES ZOSTER IN A MULTI-ETHNIC SYSTEMIC LUPUS ERYTHEMATOSUS (SLE) COHORT: CLINICAL FEATURES AND RISK FACTORS}

S. S. Shaharir ${ }^{1}$, S. Rajalingham ${ }^{1}$, R. Mohd ${ }^{2}$, N. Kori ${ }^{3}$, A. Jamil ${ }^{4}{ }^{1}$ Universiti Kebangsaan Malaysia Medical Centre, Rheumatology Unit, Department of Internal Medicine, Kuala Lumpur, Malaysia; ${ }^{2}$ Universiti Kebangsaan Malaysia Medical Centre, Nephrology Unit, Department of Internal Medicine, Kuala Lumpur, Malaysia; ${ }^{3}$ Universiti Kebangsaan Malaysia Medical Centre, Infectious Disease Unit, Department of Internal Medicine, KL, Malaysia; ${ }^{4}$ Universiti Kebangsaan Malaysia Medical Centre, Dermatology Unit, Department of Internal Medicine, Kuala Lumpur, Malaysia

Background: Systemic Lupus Erythematosus (SLE) patients are at risk of Herpes Zoster $(\mathrm{HZ})$ infection due to the underlying immunosuppressed state. The reported incidence of $\mathrm{HZ}$ in SLE is 6 to 10 -times higher than the general population.

Objectives: To determine the clinical characteristics of SLE patients who develop Herpes Zoster ( $\mathrm{HZ}$ ) infection and their associated risk factors.

Methods: Medical records review was performed on consecutive SLE patients in Universiti Kebangsaan Malaysia Medical Centre (UKMMC) from 2018 until 2019 Previous history of $\mathrm{HZ}$ and their demographic characteristics, clinical and medications used at the time of infection were recorded. Univariate and multivariate analyses were performed to compare the clinical and treatment characteristics 
between SLE patients with history of $\mathrm{HZ}$ and patients who had never had experienced $\mathrm{HZ}$.

Results: A total of 229 patients with predominantly Malay patients $(n=123$ $53.7 \%)$, followed by Chinese $(n=90,39.3 \%)$ and others $(n=16,7.0 \%)$ were included. A total of 37 patients had history of $\mathrm{HZ}(16.2 \%)$. Their mean age during $\mathrm{HZ}$ episode was $34.4 \pm 13.8$ years and their SLE disease duration was 68.7 \pm 57.1 months. More than half of them $(n=21,56.8 \%)$ developed $H Z$ when the SLE disease was active with the mean dose of prednisolone at the time of infection was $20.7 \pm 9.2 \mathrm{mg}$ daily. A total of $21 \mathrm{HZ}$ patients $(56.8 \%)$ had ever received cyclophosphamide with the median interval of the last infusion was $6(0.2-84)$ months. Almost half of the $\mathrm{HZ}$ patients $(n=18,48.6 \%)$ developed the infection while on cyclosporine A. Meanwhile, 4 (10.8\%) were on azathioprine and mycophenolate mofetil respectively. Chinese patients tend to have $\mathrm{HZ}$ as compared to other ethnics ( $27 \%$ vs $41.7 \%$ ), $\mathrm{p}=0.07$. $\mathrm{HZ}$ occurred in a higher proportion among male patients $(29 \%)$ as compared to female patients $(14.1 \%), p=0.05$. The use of azathioprine $(10.8 \%$ vs $55.2 \%, p<0.01)$ and mycophenolate mofetil $(10.8 \%$ vs $31.8 \%, p=0.009$ ) were less associated with $\mathrm{HZ}$. On the other hand, the use of cyclosporine A ( $48.6 \%$ vs $32.3 \%, p=0.05)$ and prednisolone $\geq 60 \mathrm{mg}$ daily $(44.4 \%$ vs $28 \%, \mathrm{p}=0.04$ ) were associated with $\mathrm{HZ}$. Higher $\mathrm{HZ}$ patients had hematological manifestation $(81.1 \%$ vs $62.5 \%, p=0.04)$ and positive lupus anticoagulant (LA), $32.4 \%$ vs $14.6 \%, p=0.02$. A forward logistic regression which included all factors with $p<0.1$ in the univariate analyses revealed that the use of prednisolone $\geq$ $60 \mathrm{mg}$ daily and hematological manifestation were the independent predictors of $\mathrm{HZ}$ with $\mathrm{OR}=2.28(95 \% \mathrm{C} . \mathrm{I}=1.01-5.17), \mathrm{p}=0.049$ and $\mathrm{OR}=2.78(95 \% \mathrm{C} . \mathrm{I}=1.09$ 7.04), $p=0.03$ respectively. The use of azathioprine was associated with a lower risk of $\mathrm{HZ}$ with OR 0.08 (95\% C. I= 0.03-0.25), $\mathrm{p}=<0.01$.

Conclusion: Our study demonstrated the possible influence of male gender, Chinese ethnicity and disease characteristics such as hematological manifestation and lupus anticoagulant positivity with the occurrence of $\mathrm{HZ}$. In addition, the use high dose oral prednisolone $\geq 60 \mathrm{mg}$ daily was the independent predictor of $\mathrm{HZ}$ while on the other hand, the use of azathioprine was associated with a lowe risk of developing $\mathrm{HZ}$ as compared to other immunosuppressive agents. Further larger studies are needed to confirm these associations.

\section{REFERENCES:}

[1] Chen D, Li H, Xie J, Zhan Z, Liang L, Yang X. Herpes zoster in patients with systemic lupus erythematosus: Clinical features, complications and risk factors. Exp Ther Med. 2017;14(6):6222-6228.

Disclosure of Interests: None declared

DOI: 10.1136/annrheumdis-2021-eular.1216

\section{POS0724 GENDER DIFFERENCES IN THROMBOTIC PRIMARY ANTIPHOSPHOLIPID SYNDROME IN A LARGE COHORT OF PATIENTS FROM FOUR EUROPEAN CENTERS}

L. Moschetti ${ }^{1}$, L. Dal Pozzolo ${ }^{1}$, V. Le Guern ${ }^{2}$, N. Morel ${ }^{2}$, C. M. Yelnik ${ }^{3}$, M. Lambert ${ }^{3}$, E. Hachulla ${ }^{3}$, Y. Benhamou ${ }^{4}$, F. Franceschini ${ }^{1}$, L. Andreoli ${ }^{1}$, N. Costedoat-Chalumeau ${ }^{2}$, A. Tincani ${ }^{1} .{ }^{1}$ ASST Spedali Civili - University of Brescia, Rheumatology and Clinical Immunology Unit - Clincal and Experimental Sciences, Brescia, Italy; ${ }^{2} 2 A P-H A$ Cochin Hospital - Université Descartes-Sorbonne Paris Cité, Internal Medicine Departement, Centre de Référence Maladies auto-immunes et systémiques rares d'ile de France, Paris, France; ${ }^{3}$ Univ Lille, INSERM, CHU Lille, Service de médecine interne et d'immulogie clinique, Centre de Réference des Maladies auto-immunes systèmiques rares du nord-ouest de France (CeRAINO), U1167 - RID AGE, Lille, France; ${ }^{4} \mathrm{CHU}$ Charles Nicolle - Normandie University, UNIROUEN, Départemend de Médecine Interne - INSERM U1096 EnVI, Rouen, France

Background: Autoimmune diseases occur more frequently in females and their course and severity can be affected by gender. Antiphospholipid syndrome (APS) is a systemic autoimmune disorder in which antiphospholipid antibodies (aPL) exert a pathogenic role resulting in vascular thrombosis and/or pregnancy morbidities. Data about gender differences in thrombotic APS (t-APS) are still scarce $^{1,2}$.

Objectives: To evaluate the differences in frequency, disease expression and severity between females and males affected by primary t-APS.

Methods: Retrospective study enrolling subjects with a formal diagnosis of primary APS (Miyakis 2006) with vascular thrombosis at onset. Women who presented with obstetric events as first aPL-related manifestation were excluded. All the patients were followed from 1967 to 2019 in four European centers: three French centers and one Italian center.

Results: The study included 433 patients (68\% females, $32 \%$ males). Median age at t-APS onset [31 (24-46) vs $41(29-53)$ years, $p<0.001]$ and at diagnosis [34 (27-50) vs $46(34-57)$ years, $p<0.001]$ was significantly lower in females.

The most common presenting manifestations were venous thrombosis $(60 \%)$ followed by arterial events (37\%) and catastrophic APS (3\%). Venous events were more frequent in women as compared to men (64\% vs 51\% p:0.012 OR:1.7 [1.1-2.5]). Sites of venous thrombosis included: limbs (35\%), pulmonary (17\%), cerebral (3\%), portal and inferior cava (2\%) and retinal (1\%) veins, without gender differences. The arterial events were more frequent among men $(43 \%$ vs $34 \%$ p:0.053). Strokes (27\%) and myocardial infarctions (4\%) were the most frequent manifestations, followed by thrombosis of limbs (2\%), retina (2\%) and abdominal organs (1\%). Noteworthy, only men presented with visceral ischemia. During the follow-up, new thrombosis occurred in $41 \%$ of patients (179/433). $33 \%$ out of them had at least two episodes and these occurred especially among males (22\% vs $10 \%$ p:0.001 OR:2.5 [1.3-4.8]). New events were mostly of the same type, but $1 / 3$ of patients presented a switch from venous to arterial side and viceversa, with no gender differences.

Complete aPL profile was available in 357 subjects: $33 \%$ had single aPL positivity, $24 \%$ double positivity and $43 \%$ triple positivity, with no differences between women and men. About $80 \%$ of the patients had a concomitant risk factor (RF) for thrombosis. Established cardiovascular RFs were more represented among men as shown in table 1. In women, estrogenic exposure was the main RFs, present in almost $40 \%$ of them.

Table 1

\begin{tabular}{|c|c|c|c|}
\hline & $\begin{array}{r}\text { MALES } \\
n=137\end{array}$ & $\begin{array}{c}\text { FEMALES } \\
n=296\end{array}$ & $\begin{array}{c}P \\
\text { OR [IC 95\%] }\end{array}$ \\
\hline \multicolumn{4}{|c|}{ Traditional cardiovascular RFs, $\mathbf{n}(\%)$} \\
\hline Smoke & $66(48)$ & $81(27)$ & $\begin{array}{c}<0.001 \\
2.5[1.6-3.8]\end{array}$ \\
\hline Arterial hypertension & $59(43)$ & $75(25)$ & $\begin{array}{c}<0.001 \\
2.2[1.5-3.4]\end{array}$ \\
\hline Dyslipidemia & $52(38)$ & $72(24)$ & $\begin{array}{c}0.004 \\
1.9[1.2-2.9]\end{array}$ \\
\hline Diabetes & $16(12)$ & $15(5)$ & $\begin{array}{c}0.014 \\
2.5[1.8-5.1]\end{array}$ \\
\hline \multicolumn{4}{|l|}{ Other thrombophilic factors, $n(\%)$} \\
\hline Estrogenic stimuli* & 0 & $116(39)$ & - \\
\hline Trauma / surgery / immobilization & $21(15)$ & $32(11)$ & $n s$ \\
\hline Congenital thrombophilia & 9/94 (10) & $33 / 204$ (16) & $n s$ \\
\hline
\end{tabular}

Data were compared using contingency tables, $p$ value was calculated with Chi-Squared or Fisher exact test. * = hormonal therapy, pregnancy, post-partum

Conclusion: This gender-oriented analysis of patients with primary t-APS showed that women had the first vascular event at a younger age and mostly on the venous side, while men presented mainly with arterial events, later in life and suffered from more recurrent events. No differences were observed in the distribution of the aPL profile. The different frequency of arterial and venous events in the two groups could be attributed mainly to the presence of additional RFs rather than to biological gender-specific issues. However, it should be underlined that some RFs, such as the use of estrogens or classic cardiovascular RFs, are exclusive or more represented in one gender rather than the other, making it difficult to assess the link of causality between gender and manifestations of t-APS. REFERENCES:

[1] JF de Carvalho. Rheumatol Int. 2011.

[2] LJ Jara. Lupus. 2005.

Disclosure of Interests: None declared

DOI: 10.1136/annrheumdis-2021-eular.1228

\section{POS0725 CLINICAL AND IMMUNOLOGICAL CHARACTERISTICS OF PATIENTS WITH JUVENILE-, ADULT- AND LATE- ONSET SYSTEMIC LUPUS ERYTHEMATOSUS}

O. Iaremenko ${ }^{1}$, D. Koliadenko ${ }^{1}$, I. Matiyashchuk ${ }^{2} .{ }^{1}$ Bogomolets National Medical University, Department of Internal Medicine \#3, Kyiv, Ukraine; ${ }^{2}$ Medical Center "Consilium Medical", Rheumatology Department, Kyiv, Ukraine

Background: Systemic lupus erythematosus (SLE) predominantly develops in women of child-bearing age. However, nearly $20 \%$ of cases present during childhood, generally after puberty (juvenile-onset SLE, JSLE). On the other hand $10-20 \%$ of patients develop SLE after the age of $45-50$ years (late-onset SLE LSLE) [1]. It is known that age at disease onset can influence the clinical presentation and course of SLE, but the findings are not always consistent across the studies [2].

Objectives: The aim of this study was to evaluate the spectrum of clinical manifestations and autoantibody profile in patients with SLE in the central region of Ukraine regarding age at onset.

Methods: The study included 258 SLE patients before starting an adequate therapy, comprising 225 females (87.2\%) and 33 males (12.8\%). The median age at SLE onset was $28(20-39)$ years. The patients were classified into 3 groups: - age at SLE onset $\leq 18$ years (JSLE; $n=52 ; 20.2 \%$ ), II - SLE onset at age 19-44 years (adult-onset SLE, ASLE; $n=161 ; 62.4 \%$ ), III - age at disease onset $\geq 45$ years (LSLE; $n=45 ; 17.4 \%$ ). The clinical and demographic data, SLE Disease Activity Index (SLEDAI), erythrocyte sedimentation rate (ESR), C-reactive protein 